\title{
AS ARMADILHAS DA GRATIDÃO: O PODER E O CÓDIGO SENTIMENTAL EM HELENA
}

\author{
ANDRÉ CABRAL DE ALMEIDA CARDOSO \\ Universidade Federal Fluminense \\ Niterói, Rio de Janeiro, Brasil
}

Resumo: Helena é o romance mais sentimental de Machado de Assis. No entanto, a tradição sentimental é articulada de forma extremamente complexa e problemática nessa obra. O objetivo deste trabalho é examinar como essa tradição é explorada em Helena para revelar as relações de poder que caracterizavam o convívio social na época de Machado, dominada pelo patriarcalismo, e que os romances brasileiros que o antecederam procuravam contornar. Em Helena, o código sentimental surge como uma maneira de mediar essas relações de poder, ao mesmo tempo em que as reproduz, demonstrando as contradições presentes na maneira como esse código era apropriado nos romances brasileiros do século XIX e dando-lhe um novo significado.

Palavras-chave: código sentimental; patriarcalismo; relações de poder; romance brasileiro do século XIX; Helena

\section{THE TRAPPINGS OF GRATITUDE: POWER AND THE SENTIMENTAL CODE IN HELENA}

\begin{abstract}
Helena is the most sentimental of Machado de Assis's novels. However, the sentimental tradition is articulated in an extremely complex and problematic way in this novel. The aim of this paper is to examine how this tradition is explored in Helena to reveal the power relations that characterized the patriarchal society in which Machado lived, and which earlier Brazilian novels tried to dodge. In Helena, the sentimental code functions as a means to mediate between these power relations, while it perpetuates them, revealing the contradictions in the way this code was appropriated in nineteenth-century Brazilian novels and giving it a new meaning.
\end{abstract}

Keywords: sentimental code; patriarchy; power relations; nineteenth-century Brazilian novel; Helena 
$\mathrm{Q}$ uando publicado, em 1876, Helena foi bem recebido pela crítica e teve certa popularidade; pouco depois, porém, seria rejeitado pela maioria dos críticos literários brasileiros, provavelmente por ser o romance mais melodramático e sentimental de Machado de Assis, como Hélio de Seixas Guimarães observa. Para Guimarães, a rejeição de Helena pela maior parte da crítica seria natural, levando-se em conta o desenvolvimento da produção de Machado a partir de Memórias póstumas de Brás Cubas. No entender do pesquisador, entretanto, os aspectos sentimentais e melodramáticos do romance não seriam um "acidente ou desvio de rota", configurando-se, na verdade, num "registro não apenas reivindicado pelo público leitor contemporâneo como buscado pelo escritor, que o utiliza como estratégia para atingir o público leitor de folhetim". Guimarães levanta então a possibilidade de que o Machado da segunda fase é que representaria um desvio de rota, provocado pela constatação do escritor de que o melodrama e a ficção popular não davam conta de representar com o mínimo de verossimilhança as relações da sociedade brasileira. ${ }^{1}$

Helena seria, portanto, mais um exemplo da enorme influência que a literatura sentimental exerceu sobre os primeiros romances brasileiros, mas seria também um projeto frustrado, se comparado aos romances de Machado que vieram a seguir. No entanto, eu gostaria de argumentar que Helena apresenta certa complexidade, não só por sua posição no processo de transição para o Machado da segunda fase, mas também pela relação tensa que mantém com a tradição sentimental da qual ainda faria parte. Helena apresenta sinais não só de uma insatisfação com a maneira como essa tradição vinha sendo explorada na literatura brasileira até então, mas também de uma tentativa de empregar recursos da literatura sentimental, muito familiares ao público leitor e ao próprio escritor, para começar a trabalhar algumas das tensões que Machado exploraria de forma mais aprofundada nos romances da segunda fase. Ainda que se aceite a avaliação de Helena como um romance falho, de composição irregular, que não cumpre as expectativas que ele próprio levanta, ${ }^{2}$ a obra é um estágio necessário na elaboração dos elementos temáticos e formais que caracterizariam a ficção de Machado desse ponto em diante. Parte de suas incongruências se deve à apropriação de elementos da tradição sentimental, que surgem na narrativa de forma contraditória, apontando para os perigos e dificuldades que essa tradição enfrenta dentro de uma ordem patriarcal diferente do contexto em que ela surgiu originalmente.

${ }^{1}$ GUIMARÃES, Os leitores de Machado de Assis: o romance machadiano e o público de literatura no século 19, p. 156-57, 159-61.

${ }^{2}$ Idem, p. 160-161. 
A fim de entender essas contradições, será preciso traçar um breve esboço do papel do sentimentalismo no romance brasileiro do século XIX. Depois disso, irei discutir como elementos da tradição sentimental são empregados de forma problemática em Helena, focando principalmente nas relações de poder que se delineiam entre alguns de seus personagens principais.

\section{O código sentimental}

A ficção sentimental surgiu na Europa no século XVIII, com a publicação de Pamela, de Samuel Richardson, em 1740-41, e de Julie ou la Nouvelle Hélö̈se, de Rousseau, em 1761. Sua influência logo seria sentida não só na literatura, mas também na filosofia, na medicina, na religião e no comportamento social como um todo, configurando o que G. J. Barker-Benfield chama de uma "cultura da sensibilidade" que desempenharia um papel importante no pensamento do século XVIII. Na verdade, seria possível usar a noção de código proposta por Niklas Luhmann para falar de um código sentimental como um meio de comunicação estruturado socialmente e dotado de sua própria semântica e retórica. O código sentimental está estruturado em torno de um conjunto de conceitos, símbolos e valores morais específicos, como a noção de sensibilidade (a capacidade de reagir a estímulos físicos e emocionais) e simpatia, que Adam Smith define como a capacidade de imaginar o que outra pessoa sente numa determinada situação e de se identificar com ela. ${ }^{3} \mathrm{O}$ código sentimental fez parte do esforço da burguesia para impor sua ideologia de domesticidade, frugalidade e trabalho (valores morais inseridos no código) e para imaginar relações sociais baseadas na identificação e na sensibilidade como uma alternativa para a rígida hierarquia social imposta pela aristocracia.

Os romances sentimentais tiveram ampla circulação no Brasil ao longo de todo o século XIX, ocupando uma posição de destaque nas listas de livros à venda publicadas por jornais como o Diário do Rio de Janeiro, sobretudo na primeira metade do século. Essas listas costumam se resumir a uma enumeração de títulos, em geral sem nenhuma referência ao autor; às vezes, porém, um pequeno

\footnotetext{
${ }^{3}$ SMITH, The Theory of Moral Sentiments, p. 3. A palavra "simpatia" era usada frequentemente por escritores como Alencar num sentido semelhante à definição oferecida por Adam Smith, dentro, portanto, de uma estética sentimental. Apesar de os dicionários ainda trazerem esse sentido para a palavra "simpatia", no uso cotidiano seu significado se modificou. Hoje uma palavra mais próxima para se referir a esse conceito seria "empatia", que tem um alcance mais amplo que "compaixão", pois indica uma ressonância com qualquer tipo de sentimento, e não apenas com aqueles considerados dolorosos.
} 
parágrafo anuncia um item específico, empregando com frequência uma retórica sentimental concentrada:

A Moura Encantada é uma d'essas melancolicas harmonias, ou um d'esses patheticos accordos que [palavra ilegível] amor tira d'alma, ahi vibrando a magica corda sentimental languidamente afinada por uma sympathia extremada nas delicias de um amor tão puro, como um coração de virgem, que ama só porque ama. ${ }^{4}$

Não é difícil encontrar exemplos semelhantes dessa retórica em muitos dos principais romances brasileiros publicados no século XIX, desde as obras de Joaquim Manuel de Macedo até do próprio Machado de Assis, passando por José de Alencar e Bernardo Guimarães. Se romances típicos da tradição sentimental, como Claire d'Albe, Élisabeth, ou les exilés de Sibérie, e Caroline de Lichtfield, para não falar dos próprios Pamela, Clarissa e Julie ou la nouvelle Heloüse, circulavam amplamente no Brasil, a tradição sentimental se manifesta nos romances brasileiros não tanto como um subgênero bem definido, mas sim como uma retórica carregada de aspirações próprias e de profundo sentido ideológico que se pode manifestar, em diferentes graus, em romances de gêneros diferentes, como a comédia de costumes $A$ Moreninha ou a narrativa indianista $O$ Guarani. Como se pode perceber no pequeno parágrafo anunciando $A$ moura encantada, um aspecto central da maneira como o código sentimental foi apropriado no Brasil é a preocupação com a sociabilidade, com a capacidade da sensibilidade de estabelecer uma ligação com o outro, principalmente através da compaixão. A sensibilidade e a empatia, apesar de dizerem respeito a fenômenos que ocorrem dentro do indivíduo, também envolvem uma relação entre o indivíduo e o mundo exterior, assumindo, portanto, uma dimensão social. ${ }^{5} \mathrm{O}$ código sentimental poderia ser visto como uma maneira de estabelecer ou imaginar relações sociais, um estágio no desenvolvimento de um código para regular relacionamentos íntimos que, para Luhmann, começa a surgir no final do século XVII, à medida que o indivíduo se diferencia cada vez mais do resto da sociedade. Isso só seria possível numa sociedade em que o indivíduo se relaciona com o seu meio de acordo com as funções que ele exerce, e não de acordo com a sua inserção numa posição hierárquica.

\footnotetext{
${ }^{4}$ Diário do Rio de Janeiro, set. 1845.

5 Paul Ricœur também chama atenção para a centralidade da compaixão, ou da simpatia (no sentido que Smith dá ao termo), para o estabelecimento de laços sociais, apontando-a como traço constituinte da identidade humana. Ver RICEUR, O si-mesmo como outro, p. 197-214.
} 
São essas as condições que se delineiam na Europa do século XVIII, época em que a cultura sentimental atingiu o seu auge. No Brasil do século XIX, apesar da presença de uma sociedade escravocrata extremamente hierárquica, a sensibilidade também agia como forma de imaginar relações sociais que contornavam ou neutralizavam as estruturas de poder vigentes. O caso mais emblemático se encontra em A escrava Isaura, de Bernardo Guimarães, cuja personagem-título efetiva sua escalada social graças à sua extrema sensibilidade, cuidadosamente pintada desde as primeiras páginas do romance. Não se trata de um caso isolado. De A Moreninha a Til ou $O$ Guarani, a sensibilidade é tratada como elemento desencadeador de identificações que transpõem os abismos sociais e que oferecem a possibilidade de desarmar todo tipo de conflito. Mesmo em Senhora, provavelmente o romance urbano de Alencar em que a questão da desigualdade social é tratada com maior crueza, a sensibilidade natural de Aurélia e os elos sentimentais que a ligam a Seixas efetuam a reconciliação do casal no final do romance. $\mathrm{O}$ dinheiro, apresentado de forma extremamente negativa ao longo da narrativa, acaba se tornando um elemento de união: o pagamento que Seixas recebera de Aurélia para se casar com ela, e que ele devolve no desfecho do romance, é convertido numa doação caridosa para uma protegida de Aurélia, servindo não só como prova da restauração moral de Seixas, mas também da afinidade sentimental entre os personagens, responsável por uma nova harmonia social.

Intimamente ligado à função da sensibilidade e da empatia como bases imaginárias para relações sociais cordiais, manifesta-se também nos romances brasileiros de boa parte do século XIX outro traço da cultura sentimental: um fascínio pela transparência, na maioria das vezes aliada a uma inocência infantil. Desde a Moreninha de Macedo, as protagonistas desses romances tendem a ser apresentadas quase como meninas. Na ficção de Alencar, em particular, a inocência costuma ser representada como um retorno à infância. O exemplo mais marcante é a Lúcia, de Lucíola, cuja trajetória de volta rumo à pureza é marcada por uma visita à casa onde ela passara a infância, visita durante a qual ela apaga simbolicamente seu passado como prostituta, coroação de um processo em que Lúcia ia se tornando cada vez mais como "uma menina de quinze anos, pura e cândida". ${ }^{6}$ A restauração da inocência de Lúcia atinge o seu auge no momento de sua morte, quando a opacidade de seu corpo é apagada, deixando apenas a transparência de sua alma: "Um sorriso pálido desfolhou-se ainda nos lábios sem

${ }^{6}$ ALENCAR, Lucíola, p. 102. 
cores: sublime êxtase iluminou a suave transparência de seu rosto. A beleza imaterial dos anjos deve ter aquela divina limpidez". ${ }^{7}$

O percurso de Lúcia para reconquistar a sua inocência infantil envolve não só a reafirmação de sua transparência, mas também o seu recolhimento do mundo, o abandono da ostentação e a dedicação à vida doméstica, assumindo as características que as heroínas sentimentais costumam apresentar em seu ponto de partida. A vitalidade do código sentimental pode ser percebida, ainda no final do século XIX, na evocação de valores semelhantes na nota que Machado de Assis publica na revista $A$ Estação por ocasião da morte do editor Henrique Lombaerts, em julho de 1897:

Não é demais dizer que foi um exemplo a vida deste homem, um exemplo especial, porque ao esforço continuado e efficaz, ao trabalho de todos os dias e de todas as horas não juntou o ruido exterior. Relativamente expirou obscuro; o tempo que lhe sobrava da direcção da casa era dado á esposa, e, quando perdeu a esposa, ás suas recordações de viuvo. ${ }^{8}$

Nas palavras de Machado, Lombaerts surge como um exemplo das virtudes domésticas e da discrição, de uma ética de trabalho que não se deixa levar pelo desejo de brilhar na sociedade, privilegiando as relações mais autênticas no seio da família. Não há conflito entre a dedicação profissional e a devoção ao lar, que aponta para a estabilidade de uma convivência harmônica para além da morte. $\mathrm{O}$ apego sentimental surge mais uma vez como garantidor da harmonia das relações sociais, uma vez que a atividade profissional parece uma extensão da lógica que rege o convívio íntimo.

Trata-se, é claro, de uma visão oficial e idealizada de Henrique Lombaerts. O interessante é que essa visão está calcada nos princípios do código sentimental, que ainda surgem como norteadores do que é desejável em sociedade. No entanto, já em Helena, Machado demonstrava que esse edifício que aparentava uma absoluta harmonia apresentava fissuras que trincavam toda a sua estrutura.

\section{O poder do pai e a lógica da mãe}

Helena possui os atributos tradicionais de uma heroína sentimental. Seu porte é elegante, mas, em vez de arrogância, revela atitudes modestas e recatadas;

\footnotetext{
${ }^{7}$ Idem, p. 126.

${ }^{8}$ A Estação, 15 jul. 1897, s/p.
} 
seu rosto é levemente moreno, mas mesmo assim ruboriza com facilidade, e suas linhas são "puras e severas". Além disso, ela é "dócil, afável, inteligente". ${ }^{9}$ Seus atributos físicos e psicológicos revelam beleza, recato, simplicidade, espontaneidade e pureza, todos valores importantes no código sentimental. Sua tez lembra as tentativas românticas de criar um ideal de beleza genuinamente brasileiro, mas também é uma forma de demonstrar sua transparência, pois revela seus sentimentos através de reações físicas como o rubor..$^{10}$ Além disso, Helena não foge à regra de aliar essa transparência a uma inocência infantil.

Estácio também é um personagem sentimental, com qualidades semelhantes às de Helena. Ele fora criado longe da sociedade e vivia "a vida de família, na idade em que outros, seus companheiros, viviam a das ruas e perdiam em cousas ínfimas a virgindade das primeiras sensações". Ele é inocente, casto e reservado, dotado de "uma gravidade jovial e familiar, igualmente distante da frivolidade e do tédio, uma compostura do corpo e do espírito, temperada pelo viço dos sentimentos e pela graça das maneiras". Finalmente, "juntava às outras qualidades morais uma sensibilidade, não feminil e doentia, mas sóbria e forte".11

O narrador chama atenção para o fato de que Estácio herdou seu caráter da mãe, da qual é em grande parte um reflexo, e a necessidade de frisar que sua sensibilidade não era excessivamente feminina revela o risco de essa identificação levar à perda de sua masculinidade. É provável que a relutância de Estácio em assumir o papel ativo que se espera dele como o novo chefe da família seja um efeito da passividade que costuma caracterizar o protagonista sentimental. Essa passividade se deve não só ao fato de a sensibilidade ser uma caraterística essencialmente reativa aos estímulos do meio, mas surge também como uma marca da fragilidade do personagem, que frequentemente se encontra numa posição de derrota em relação ao mundo social. Essa derrota, porém, se limita aos aspectos convencionais da sociedade, como a ideia de sucesso material e a

\footnotetext{
${ }^{9}$ ASSIS, Helena, cap. 3, p. 283; cap. 4, p. 286.

${ }^{10}$ A ideia de transparência era particularmente importante para Rousseau, e é possível que o valor que ela adquiriu no código sentimental se deva em parte a sua influência. Ver STAROBINSKI, Jean-Jacques Rousseau: La transparence et l'obstacle, suivi de Sept essais sur Rousseau, e MÜCKE, Virtue and the Veil of Illusion: Generic Innovation and the Pedagogical Project in Eighteenth-Century Literature.

${ }^{11}$ ASSIS, Helena, cap. 2, p. 280. O valor dado ao recolhimento também remonta a Rousseau, ao estado idealizado do selvagem ainda não corrompido pela civilização, delineado principalmente no Discours sur l'origine et les fondemens de l'inégalité parmi les hommes. A criação longe da sociedade urbana seria uma garantia de pureza e é um aspecto marcante e bastante generalizado das heroínas sentimentais, como as protagonistas de Adèle de Sénange, de Adelaïde de Souza, Élisabeth, ou les exilés de Sibérie, de Sophie Cottin e Paul et Virginie, de Bernardin de Saint-Pierre, para mencionar apenas alguns dos romances sentimentais nomeados com frequência nas listas de livros à venda divulgadas pelo Diário do Rio de Janeiro na primeira metade do século XIX.
} 
necessidade de se adequar a tudo aquilo que mundanamente se considera elegante. $\mathrm{O}$ fracasso do protagonista sentimental no mundo, na verdade, é prova de sua virtude moral e de sua integridade espiritual. Como observa Brissenden, ${ }^{12}$ a falta de poder efetivo no mundo reforça, nesses personagens, o elevado poder espiritual de sua virtude, que é símbolo de seu valor e liberdade como indivíduos. No entanto, a maneira como esses traços essencialmente sentimentais se distribuem fartamente entre os personagens de Helena traz tensões insolúveis, principalmente no que diz respeito à relação de Estácio com o mundo - problema que já começa a se esboçar na observação de que ele, como costuma ser o caso das heroínas sentimentais, havia sido criado à parte da sociedade.

Ao se tornar "o herdeiro [das] robustas qualidades" da mãe (e não do pai), ${ }^{13}$ Estácio de certa forma torna-se um substituto desta, ocupando a posição oposta à de seu pai na arena moral delineada no romance, uma vez que o comendador Vale fizera sofrer muito a esposa, apresentada como vítima resignada e nobre - e também, mais uma vez, passiva - de seus desmandos. A maneira como Estácio é apresentado nas primeiras páginas de Helena, portanto, parece colocá-lo como uma alternativa para o poder patriarcal do pai, que seria substituído por uma ordem mais feminina e doméstica, em que a sobriedade e o recato são temperados pela delicadeza do sentimento. A maneira como acolhe Helena parece um sinal disso, uma vez que se baseia menos na necessidade de manter a autoridade paterna do que no desejo de manter ou criar elos emocionais:

- Não quero saber, disse ele, se há excesso na disposição testamentária de meu pai. Se o há, é legítimo, justificável pelo menos; ele sabia ser pai; seu amor dividia-se inteiro. Receberei esta irmã, como se fora criada comigo. Minha mãe faria com certeza a mesma cousa. ${ }^{14}$

Ainda que a autoridade do pai seja reforçada aqui, é importante observar que ela não se impõe por si só. A fim de cumprir as exigências do testamento, Estácio primeiro converte a autoridade paterna em um amor que ele está disposto a compartilhar. A norma a que ele obedece não é bem o poder arbitrário do pai, mas a lógica da mãe, como Estácio deixa claro ao afirmar que sua mãe teria agido da mesma maneira. Ocorre, então, uma identificação mais profunda com a mãe, já que Estácio só consegue reformular a autoridade paterna porque está agindo da

\footnotetext{
${ }^{12}$ BRISSENDEN, Virtue in Distress: Studies in the Novel of Sentiment from Richardson to Sade, p. 91, 129, 135.

${ }^{13}$ ASSIS, Helena, cap. 2, p. 280.

14 Idem, cap. 2, p. 279.
} 
mesma forma como sua mãe agiria. Mais uma vez, ele é colocado no mesmo lado da mãe e exibe a mesma virtude que ela, aceitando a autoridade patriarcal com a mesma resignação com que ela suportara o abuso desse poder.

Uma típica heroína sentimental se vê presa num conflito entre seu desejo representado no enredo pelo desejo de escolher seu marido, ou de simplesmente não se casar, como a Clarissa de Richardson faz num determinado momento - e o dever de obedecer ao pai de forma incondicional. No caso específico das obras de Richardson, Terry Eagleton vê nesse conflito uma luta ideológica entre a tentativa do indivíduo de declarar sua própria liberdade e uma forma de poder patriarcal mais tradicional, que Eagleton encara como uma estrutura de poder impessoal. ${ }^{15}$

Um conflito semelhante se delineia nas páginas de Helena, expresso na luta da personagem principal para manter sua independência e respeito próprio, ao mesmo tempo em que é empurrada para uma situação que ela julga humilhante pelo dever de obedecer às suas figuras paternas. A esse conflito se soma a complicação adicional de que o poder patriarcal no Brasil, como Sérgio Buarque de Holanda observa em Raízes do Brasil, era extremamente pessoal. Isso embaralha a maneira como os diversos campos morais são definidos em Helena, pois nos vemos diante de duas formas de relações pessoais que em princípio funcionam de maneiras diferentes: o poder pessoal do patriarca, que é tirânico, egoísta e inconstante - mas que não deixa de ter uma projeção mais impessoal na lei e nas normas de conduta sociais -, e o tipo de relação pessoal baseada na compaixão e na busca de afinidades, que é amorosa e harmoniosa, prometendo dissolver, pelo menos num nível imaginário, qualquer tipo de hierarquia social.

O problema é que essas duas formas de relação se confundem em Helena. A própria figura do pai se desloca de um campo para outro: nas primeiras páginas do romance, o conselheiro Vale é uma autoridade ausente cujo poder, no entanto, permanece forte o bastante para ser respeitado do além-túmulo; mais adiante, quando o vemos num flashback, descobrimos que ele era carinhoso, e que seu desejo de que Helena fosse reconhecida como membro de sua família era fruto de sua afeição pela menina, que na verdade não era sua filha. Contudo, o que resta desse pai é seu testamento, cuja autoridade é indiscutível e que deve ser seguido à risca, por mais que suas estipulações sejam inconvenientes ou embaraçosas. É nessa mistura entre o oficial e o pessoal que o poder se faz valer em Helena, assumindo os traços de um sistema que enreda todos os personagens.

${ }^{15}$ EAGLETON, The Rape of Clarissa: Writing, Sexuality and Class Struggle in Samuel Richardson, p. 16. 
Como Gledson observa, Helena começa com um "parricídio" (a primeira frase do romance anuncia a morte do conselheiro Vale); ao mesmo tempo em que o pai é afastado, porém, sua presença é reafirmada como um elemento motor do enredo. ${ }^{16}$ Esse apagamento do pai é uma tendência que Gledson detecta desde as primeiras obras de Machado, culminando em Dom Casmurro. Ao remover o pai, Machado estaria tentando demonstrar que o poder patriarcal ainda funciona como a norma, mesmo que a pessoa que deveria exercê-lo esteja ausente. Desse modo, Machado estaria despersonalizando o poder patriarcal, mostrando como este funciona enquanto um sistema, ou como uma instituição. Segundo Gledson, em Helena esse poder estaria redistribuído entre duas autoridades masculinas, dr. Camargo e padre Melchior, que representariam os aspectos negativos e positivos do poder paterno, respectivamente. ${ }^{17}$

Eu gostaria de argumentar, porém, que, apesar da presença marcante dessas figuras paternas substitutas, o poder patriarcal em Helena age de forma bem mais difusa, afetando de diferentes maneiras o comportamento de todos os personagens do romance, muitas vezes subvertendo suas melhores intenções. Longe de pertencer a qualquer um em particular, ele se constitui numa rede de relações, como na definição foucaultiana de poder, penetrando cada indivíduo. ${ }^{18}$ Ele se manifesta nas ações e no discurso de cada personagem, de modo que a própria linguagem adquire significados diferentes de acordo com quem fala.

Num determinado ponto do romance, Estácio diz a si mesmo: "Sonâmbulo, abre os olhos, tem consciência de tuas ações; teu abraço enforca; teus escrúpulos fazem-te odioso; tua solicitude é pior do que a cólera". ${ }^{19}$ Essa autoacusação enfática ocorre logo depois de Estácio conseguir travar o noivado de Helena com seu melhor amigo, Mendonça. Estácio age nesse momento sob a justificativa da preocupação com a família e o amigo, argumentando que Helena na verdade não ama Mendonça e iria casar-se com ele apenas por estima, que é a "flor da razão", enquanto "a flor do sentimento é muito mais própria no canteiro do matrimônio". ${ }^{20}$ Esse uso banal e forçado da retórica sentimental serve para disfarçar sua verdadeira motivação: guardar Helena para si próprio.

${ }^{16}$ GLEDSON, The Deceptive Realism of Machado de Assis: a Dissenting Interpretation of Dom Casmurro, p. 63.

${ }^{17}$ Idem, p. 60-61, 63.

${ }^{18}$ FOUCAULT, Surveiller et punir, p. 35.

${ }^{19}$ ASSIS, Helena, cap. 19, p. 348.

${ }^{20}$ Ibidem. 
$\mathrm{O}$ aspecto sistêmico do poder patriarcal se manifesta aqui pelo fato de Estácio exercê-lo inconscientemente para realizar um desejo que ele não pode admitir nem para si mesmo. Isso se dá simplesmente por causa da posição social que ele ocupa, que faz com que suas intervenções tenham consequências que ele não controla conscientemente, como o próprio Estácio reconhece ao perceber que havia impedido o noivado de Helena, sem precisar proibi-lo explicitamente. $\mathrm{O}$ horror que Estácio sente diante desse exercício de poder revela o quanto este é estranho ao seu caráter. Apresentado como um possível agente de resistência ao poder patriarcal através de sua identificação com a mãe e sua condição de personagem sentimental, Estácio mesmo assim se torna, quase sem querer, um representante desse poder.

O funcionamento do poder patriarcal como um sistema também se torna evidente ao examinarmos a entrada de Helena na família Vale. Sua sensibilidade e sua virtude se somam à sua educação, seu talento musical e sua habilidade de conversar; todos são "prendas de sociedade"21 essenciais para sua aceitação em seu novo meio. Os atributos sentimentais da virtude, sensibilidade e recato são transformados em marcas sociais cujo valor moral é diluído, convertendo-se em mera aparência. A eles se soma a fluidez de caráter de Helena, que, como boa heroína sentimental, reverbera e reage de forma adequada aos sentimentos e emoções daqueles que a cercam:

O que a tornava superior e lhe dava probabilidade de triunfo, era a arte de acomodar-se às circunstâncias do momento e a toda casta de espíritos, arte preciosa, que faz hábeis os homens e estimáveis as mulheres. [...] Frívola com os frívolos, grave com os que o eram, atenciosa e ouvida, sem entono nem vulgaridade. Havia nela a jovialidade da menina e a compostura da mulher feita, um acordo de virtudes domésticas e maneiras elegantes. ${ }^{22}$

A repetida referência à "arte" para descrever a fluidez de Helena, porém, não deixa de introduzir uma tensão no discurso sentimental, no qual "arte" é um elemento extremamente negativo, ligado à artificialidade e ao fingimento, em oposição à pureza, espontaneidade e transparência. Se, no entanto, essa "arte" era parte de natureza de Helena, ela se torna paradoxalmente espontânea, voltando a ocupar um espaço positivo.

${ }^{21}$ Idem, cap. 4, p. 285-86.

22 Idem, cap. 4, p. 286. 
Por outro lado, essa "arte" também era fruto das circunstâncias. Sendo assim, parecemos estar diante de uma situação em que certas tendências naturais assumem novos papéis ditados pelo contexto, e a fluidez de Helena, juntamente com seus outros atributos sentimentais, que seriam espontâneos, acabam se tornando, independentemente da vontade da personagem, um instrumento de manipulação. Trata-se de um instrumento de manipulação interessado, nem que seja pelo fato de a sobrevivência de Helena depender dele, ainda que a personagem não o empregue de forma consciente, da mesma forma que Estácio não utiliza necessariamente de forma consciente seu poder, que também está ancorado numa retórica sentimental. Isso conduz a armadilhas em que os atos mais espontâneos se tornam um exercício de poder, muitas vezes associados a impulsos que os próprios personagens não conseguem reconhecer com clareza.

\section{A transparência sentimental e a opacidade do poder}

Como Dorothea von Mücke observa, o projeto estético e moral da literatura sentimental investe na criação de um sujeito unificado que, apesar de essencialmente interiorizado, é transparente: o romance, que ganha força crescente com a disseminação da cultura impressa, apresenta o sujeito como uma presença não mediada, uma voz que expressa seus sentimentos, que tanto personagem quanto leitor podem ver de forma clara. ${ }^{23} \mathrm{Em}$ Helena, porém, o discurso sentimental torna-se cada vez mais opaco com o avançar da narrativa, ao se converter num instrumento de poder que permeia as relações entre Helena e o círculo da família Vale. Se, de acordo com a lógica de Helena, o poder muitas vezes está associado a um desejo inconsciente, o próprio discurso sentimental passa a recobrir também desejos desse tipo. Em vez de um sujeito unívoco, temos agora sujeitos cindidos, cujos desejos não são claros sequer para si mesmos.

Isso acontece, por exemplo, numa longa carta que Estácio escreve para Helena quando é obrigado a deixar o Rio de Janeiro por alguns dias e na qual afirma: "Eu não sei o que é amar o tumulto exterior; acho que é dispensar a alma e crestar a flor dos sentimentos". Esse típico exemplo da retórica sentimental, que Machado reproduziria umas duas décadas mais tarde em sua nota sobre Lombaerts, faz parte de uma fantasia em que Estácio se imagina vivendo isolado no campo com Helena. Trata-se, é claro, de uma expressão do desejo inconsciente

${ }^{23}$ MÜCKE, Virtue and the Veil of Illusion: Generic Innovation and the Pedagogical Project in EighteenthCentury Literature, p. 66. 
de Estácio de ser o único a possuir Helena como um objeto amoroso, mas também é uma fantasia de poder: "Nasci para monge... e creio que também para déspota, porque estou a planear uma vida ignorada e deserta, sem consultar tuas preferências". ${ }^{24}$

Num outro ponto do romance, quando vê Helena entrando num casebre e suspeita que ela esteja tendo um caso amoroso (na verdade ela estava visitando seu pai verdadeiro), Estácio tenta se convencer de que se tratava apenas de um engano: "'Não, dizia Estácio consigo, não é este o asilo de um Romeu de contrabando. Mora aqui alguma família pobre, que a caridade engenhosa de Helena vem afagar de longe em longe'". ${ }^{25}$ Agora, o discurso sentimental é empregado para negar o desejo sexual que Estácio teme ter descoberto em Helena, colocando-a de volta num papel adequado às normas sociais, mas também apagando um possível competidor pela sua afeição. O discurso sentimental oferece a oportunidade de criar uma narrativa através da qual Estácio controla simbolicamente a realidade, moldando-a à sua vontade. Além disso, a passagem reproduz - intencionalmente ou não - uma cena parecida de Charles et Marie, romance sentimental de Mme. de Souza mencionado com frequência nas listas de livros à venda publicadas no Diário do Rio de Janeiro. No romance francês, Marie também é observada por Charles, seu namorado, entrando às escondidas num chalé ermo. A comparação com Charles et Marie parece particularmente pertinente por este romance tratar das tentativas exageradas de Charles para controlar as ações e mesmo os desejos de Marie. O ressurgimento dessa cena em Helena indica que a questão do controle da mulher pelo homem, comum nos romances sentimentais, também ocupa uma posição central no romance de Machado.

De fato, o discurso sentimental costuma funcionar como um instrumento de dominação em Helena. Assim, Estácio apela para os sentimentos de Helena para fazê-la desistir de seu casamento com Mendonça, insistindo para que a moça reconheça a afeição que sua família tem por ela e o papel que Helena desempenha para manter sua felicidade e união. ${ }^{26}$ Estácio imagina a relação dele e da tia com Helena como uma troca afetiva, na qual o "sentimento último" que ela trouxe é recompensado pela afeição dos dois, como num contrato regido pela gratidão. ${ }^{27}$ No

\footnotetext{
${ }^{24}$ ASSIS, Helena, cap. 15, p. 332; cap. 16, p. 333-35.

${ }^{25}$ Idem, cap. 20, p. 353.

${ }^{26}$ Idem, cap. 18, p. 343-44; cap. 19, p. 347-48.

27 Idem, cap. 19, p. 350.
} 
entanto, logo se torna claro que o fardo da gratidão recai sobretudo nos ombros de Helena - e trata-se de fato de um fardo, do qual ela é lembrada em várias ocasiões:

Estácio sorriu do cálculo; logo depois ficou sério, e perguntou em tom seco:

- Já lhe negamos algum prazer que desejasse?

Helena estremeceu e ficou igualmente séria.

- Não! murmurou; minha dívida não tem limites.

Esta palavra saiu-lhe do coração. As pálpebras caíram-lhe e um véu de tristeza lhe apagou o rosto. ${ }^{28}$

O comentário de Estácio, assim como a resposta de Helena, revela o desequilíbrio de poder entre os dois, ainda mais se levarmos em consideração que esse diálogo é uma consequência da admissão de Helena de que tinha fingido que não sabia andar a cavalo para que Estácio a levasse para passear com mais prazer. Essa brincadeira poderia ser interpretada como uma tentativa de Helena de tomar o controle de sua relação com Estácio, mas a resposta dele a coloca de volta em seu lugar, lembrando-lhe de sua dívida de gratidão para com a família Vale.

Para Helena, longe de estabelecer uma relação igualitária entre indivíduos baseada na troca, a gratidão é uma dívida que ela nunca pôde saldar com Estácio, sua tia e principalmente com o conselheiro Vale, que a adotou. Mesmo assim, é essa gratidão que define sua relação com eles, ao mesmo tempo em que confirma sua posição de dependência. "Até ao ponto em que a minha vontade tem um limite, que é a sua. Por mim só nada posso decidir", ela responde quando Estácio lhe pergunta se era verdade que tinha prometido se casar com Mendonça. ${ }^{29}$ Como Helena bem sabe, seu dever exige que ela apague sua vontade e siga os desejos de Estácio sem questioná-los.

No Brasil do século XIX, seria de esperar que uma moça obedecesse ao seu irmão, sobretudo na ausência do pai. No entanto, a declaração de Helena oculta um subtexto, devido a uma informação que permanece escondida: ela sabe que na verdade não é irmã de Estácio, enquanto ele não sabe disso. Consequentemente, ela se submete à vontade de Estácio como sua dependente, não como sua irmã. Esse sentimento está por trás de outro comentário que Helena já dirigira a Estácio: "Você pode encará-la [minha posição] com olhos benignos; mas a verdade é que só as asas do favor me protegem... Pois bem, seja sempre generoso". ${ }^{30} \mathrm{O}$ fato de

\footnotetext{
${ }^{28}$ Idem, cap. 6, p. 296.

${ }^{29}$ Idem, cap. 18, p. 10.

${ }^{30}$ Idem, cap. 10, p. 315.
} 
Estácio não ver nada de estranho na declaração de Helena mostra que ele encara a situação da moça da mesma maneira, ou seja, como se ela fosse apenas sua dependente, apesar de nesse ponto do romance ele ainda acreditar que Helena fosse sua irmã.

$\mathrm{O}$ apelo de Helena à generosidade de Estácio revela como o código sentimental está envolvido no mecanismo do favor, regulando-o e reproduzindo-o, e empregando a gratidão como um elemento de controle. É altamente significativo que o momento em que a verdade a respeito de Helena é revelada seja também um dos trechos do romance em que a retórica sentimental é empregada de forma mais enfática, pois é nesse ponto que o desequilíbrio de poder entre Helena e o resto da família Vale se torna explícito. O sentimentalismo age como uma maneira de disfarçar as relações de poder em jogo; no entanto, uma vez que Estácio descobre que Helena não é sua irmã, ele se sente autorizado a exercer seu poder de forma bem mais clara: "-A lei é por nós; e nossa vontade é que nos obedeça". ${ }^{31}$ Perto do final do romance, a linguagem do sentimento e a linguagem da autoridade se misturam de forma indissolúvel: "- Ande repousar, continuou Estácio; pode adoecer, e não tem direito para tanto; nossa afeição não o consentirá nunca". ${ }^{32}$

Diante desse exercício de poder, só resta a Helena protestar de forma silenciosa, através de declarações como as que foram citadas acima, em que ela aponta para a sua situação de subordinada e para o peso da gratidão como forma de controle. A carga de retórica sentimental presente nessas declarações permite a Helena assumir mais uma vez o papel de heroína sentimental. Ela se apresenta como um corpo sofredor, cujo pesar se expressa através de gestos e cujas palavras saem "do coração", o que é um sinal de sua transparência. Helena se torna um objeto de pena para o leitor e mesmo para Estácio, que depois de cada uma dessas crises busca uma reaproximação com a moça: "Apertaram-se as mãos, e o passeio continuou nas melhores disposições do mundo. Helena deu livre curso à imaginação e ao pensamento; suas falas exprimiam, ora a sensibilidade romanesca, ora a reflexão da experiência prematura, e iam diretas à alma do irmão". ${ }^{33}$ Nesses casos, o discurso sentimental ainda cumpre sua função tradicional de conciliar diferenças e estabelecer relações pessoais. No entanto, sua transparência de certa forma é comprometida, pois, nos lábios de Helena, ele carrega uma dose de queixa e denúncia que se esconde por baixo da superfície e recobre verdades que não podem ser ditas abertamente. Além disso, no relacionamento entre Helena e

\footnotetext{
${ }^{31}$ Idem, cap. 27, p. 382.

32 Idem, cap. 28, p. 386.

${ }^{33}$ Idem, cap. 6, p. 296.
} 
Estácio, ele promove apenas aproximações temporárias, pois a distância essencial entre os dois, que é no final das contas uma diferença de classes sociais que se expressa através de um desequilíbrio de poder fundamental, nunca chega a ser solucionada no romance.

O que Helena encara no fim é o mesmo problema que os narradores dos romances brasileiros até então tentavam contornar: o fato de que toda história é passível de interpretação. Nas últimas páginas do romance, todos os fatos relacionados à trajetória de Helena já foram revelados e nada permanece oculto. Isso, porém, não é suficiente, pois Helena sabe que esses fatos serão interpretados, e, dada a sua situação social, que eles serão interpretados da pior maneira possível. Sua morte, então, representa uma tentativa de controlar sua própria narrativa. Como Lúcia, em Lucíola, ela é recompensada com uma manifestação simbólica de sua própria transparência: "A mão pálida e transparente da moribunda procurou a cabeça do mancebo; ele inclinou-a sobre a beira do leito, escondendo as lágrimas e não se atrevendo a encarar o final instante". ${ }^{34}$ A única opção de Helena para estabelecer sua transparência de forma permanente, escapando da opacidade inerente a relações mediadas pelo poder, é cortar sua conexão com Estácio e a família Vale através de sua morte. No entanto, isso não traz uma resolução dos problemas colocados pelo meio social da protagonista, pois implica a subtração de Helena de sua própria narrativa.

De acordo com Roberto Schwarz, Helena se caracterizaria justamente por não desenvolver os conflitos que a narrativa esboça e por seu tom conciliatório: se de início o romance parece criticar as atitudes de alguns personagens, como Estácio, d. Úrsula e Camargo, ele acaba reforçando seus traços positivos e sua virtude. Para Schwarz, apesar de se aproximar de uma visão mais realista da sociedade brasileira, Helena deixa de explorar de forma satisfatória as contradições dessa sociedade. ${ }^{35}$ Por outro lado, se as personagens do romance parecem boas demais e agem com a melhor das intenções, elas mesmo assim terminam por sufocar e destruir Helena.

A idealização da maior parte dos personagens de Helena, portanto, longe de ser uma medida conciliatória ou uma tentativa de suavizar conflitos, na verdade é mais um meio de demonstrar como o poder patriarcal funciona como um sistema, independentemente de intenções pessoais. Se Helena não faz isso de forma estritamente realista, é porque ainda trabalha dentro da estética sentimental que

\footnotetext{
${ }^{34}$ Idem, cap. 28, p. 389. Meu itálico.

${ }^{35}$ SCHWARZ, Ao vencedor as batatas: forma literária e processo verbal nos inícios do romance brasileiro, p. 98-99.
} 
dominava o romance brasileiro até então, tradição com a qual estabelece um diálogo. Mesmo a irresolução do conflito básico da narrativa no final de Helena mostra como esse conflito de fato não tinha solução, e como ele estava profundamente imbricado na textura da personagem principal. É nesse aspecto que Helena mais se afasta das heroínas sentimentais que a precederam: ao contrário delas, ela tem uma profunda consciência dos mecanismos sociais e das relações de poder do mundo a que ela pertence, e sabe que só pode existir dentro desse sistema.

De fato, Helena representa uma mudança de tom em relação aos romances que o precederam na tradição romântica brasileira, pois nele Machado começa a chamar atenção para as relações de poder que caracterizavam a sociedade brasileira e a questionar os pressupostos por trás do esforço de empregar o código sentimental como uma maneira de neutralizá-las ou suprimi-las. O discurso sentimental se torna ambíguo em Helena, agindo como um poder conciliatório ao mesmo tempo em que marca importantes diferenças entre os personagens. Ele aponta para a esperança de uma forma de comunicação transparente, mas torna-se opaco, recobrindo desejos inconscientes ou queixas que não podem ser feitas abertamente. Ele serve ao mesmo tempo como um instrumento para o exercício do poder e como um meio de resistir a esse mesmo poder. O código sentimental deixa de oferecer uma alternativa imaginária para as lutas de poder que caracterizam as relações pessoais no "mundo" para se revelar como uma parte integrante dessas lutas de poder e, mais especificamente, como parte do mecanismo do sistema patriarcal que moldava as relações sociais no Brasil do século XIX. Se, no final, ele parece oferecer a Helena algum tipo de liberdade, ele também faz parte da estrutura que a prendeu originalmente.

\section{Referências}

ALENCAR, José de. Lucíola. São Paulo: Ática, 1992.

ASSIS, Machado de. Helena. In: . Obra completa. Rio de Janeiro: Nova Aguilar, 1986. vol. 1, p. 271-389.

BARKER-BENFIELD, Graham John. The Culture of Sensibility: Sex and Society in Eighteenth-Century Britain. 2. ed. Chicago: University of Chicago Press, 1996.

BRISSENDEN, Robert Francis. Virtue in Distress: Studies in the Novel of Sentiment from Richardson to Sade. Londres; Basingstoke: Macmillan, 1974. 
Diário do Rio de Janeiro. De 2 jan. 1830 a 3 nov. 1845. Consulta efetuada no acervo da Biblioteca Nacional.

EAGLETON, Terry. The Rape of Clarissa: Writing, Sexuality and Class Struggle in Samuel Richardson. Minneapolis: University of Minnesota P, 1982.

A Estação, v. 26, n. 13, 15 jul. 1897.

FOUCAULT, Michel. Surveiller et punir. Paris: Gallimard, 2006.

GLEDSON, John. The Deceptive Realism of Machado de Assis: A Dissenting Interpretation of Dom Casmurro. Liverpool: Francis Cairns, 1984.

GUIMARÃES, Hélio de Seixas. Os leitores de Machado de Assis: o romance machadiano e o público de literatura no século 19. São Paulo: Nankin; Edusp, 2004.

HOLANDA, Sérgio Buarque de. Raízes do Brasil. 26. ed. 14. reimp. São Paulo: Companhia das Letras, 2002.

LUHMANN, Niklas. Love as Passion: The Codification of Intimacy. 2a ed. Stanford: Stanford UP, 1998.

MÜCKE, Dorothea E. von. Virtue and the Veil of Illusion: Generic Innovation and the Pedagogical Project in Eighteenth-Century Literature. Stanford: Stanford UP, 1991.

RICHARDSON, Samuel. Clarissa or the History of a Young Lady. Londres: Penguin, 1985.

RICEUR, Paul. O si-mesmo como outro. São Paulo: Martins Fontes, 2014.

ROUSSEAU, Jean-Jacques. Discours sur l'origine et les fondements de l'inégalité parmi les hommes. In: _ _ Euvres complètes. Bibliothèque de la Pléiade. Paris: Gallimard, 1964, vol. 3.

SCHWARZ, Roberto. Ao vencedor as batatas: forma literária e processo verbal nos inícios do romance brasileiro. 4. ed. São Paulo: Duas Cidades, 1992.

SMITH, Adam. The Theory of Moral Sentiments. 1759. Amherst: Prometheus, 2000.

SOUZA, Adelaïde de. Charles et Marie. In: Euvres complètes. Ed. facsimilar. Paris, 1821. vol. 1, p. 325-457. Disponível em:

http://books.google.com/books?id=Fi7Ow77vZ80C\&hl=pt-BR. Acesso em: 9 dez. 2006.

STAROBINSKI, Jean. Jean-Jacques Rousseau: La transparence et l'obstacle, suivi de Sept essais sur Rousseau. Paris: Gallimard, 2000.

ANDRÉ CABRAL DE ALMEIDA CARDOSO é professor de Literaturas de Língua Inglesa, do Departamento de Letras Estrangeiras Modernas, na Universidade Federal Fluminense. E-mail: andrecac@id.uff.br. 